\title{
Chemical Composition of the Essential Oils from the Leaf, Stem-Bark and Twig of Terminalia mantaly H. Perrier (Combretaceae) from Nigeria
}

\author{
Olajumoke Mariam Owoade and David Gbenga Oke
}

\section{ABSTRACT}

The essential oils from the leaf, stem-bark and twig of Terminalia mantaly were isolated by hydrodistillation. The volatile oils analysed on Gas Chromatography (GC) and Gas Chromatography - Mass Spectrometer (GC - MS). The identified constituents were twelve, twenty-three and seventeen for the leaf, stem-bark and twig and accounted for $89.57 \%$, $\mathbf{9 5 . 7 7 \% , 9 5 . 9 2 \%}$ respectively. Hexahydrofarnesylacetone $\mathbf{3 0 . 0 5 \%}$ ) and Zpinane $(16.71 \%)$ were the main constituents in the leaf oil and nonanal $(21.16 \%)$ and heptanal $(\mathbf{1 0 . 5 7 \%})$ were principal component in the stembark volatile oil. Xylene isomers namely, meta and para $(21.98 \%-23.56 \%)$ were the major components of the twig with substantial amount of nonanal $(13.64 \%)$.

Keywords: Essential oil. GC-MS, hydrodistillation, Terminalia mantaly.

\author{
Published Online: October 30, 2020 \\ ISSN: $2684-4478$ \\ DOI : 10.24018/ejchem.2020.1.5.15 \\ O. M. Owoade \\ Department of Chemistry, University of \\ Ibadan, Nigeria. \\ (e-mail: jummykay@gmail.com) \\ D. G. Oke* \\ Industrial Chemistry Programme, Bowen \\ University, Iwo, Nigeria. \\ (e-mail: oke.david@bowen.edu.ng) \\ *Corresponding Author
}

\section{INTRODUCTION}

Terminalia is a predominantly tropical and sub-tropical genus belonging to the Combretaceae family with two hundred and fifty (250) species occurring in West Africa; Terminalia is the second largest genus in its family[1]. Terminalia mantaly (Umbrella or Madagascar tree) is an evergreen tree with higher altitude; native to Madagascar, and exotic to Kenya, Senegal, Somalia, Uganda, Tanzania, Ethiopia, Djibouti and Eritrea [2]. The plant is well known for its ethnobotanical and economical important. The tree of Terminalia mantaly is commonly use as shelter ornament, the bark of the wood which contain tannins is used for dyeing purpose. The leaf, stem-, root-bark is employed ethnomedicinally in treatment of various diseases in different regions such as: dysentery, diabetes, gastroenteritis, mouth candidiasis and digestive, postpartum care and malaria [3][5].

Analyses of the methanol extract of Terminalia mantaly L. (combretaceae) stem bark led to the identification of seven compounds namely: 3-O-methyl-4- $O$ - $\alpha$-rhamnopyranoside ellagic acid, 3-O-mehylellagic acid, arjungenin or 2,3,19,23tetrahydroxyolean-12-en-28-oïc acid, arjunglucoside or 2,3,19,23-tetrahydroxyolean-12-en-28-oïc acid glucopyranoside, $2 \alpha, 3 \alpha, 24$-trihydroxyolean-11,13(18)-dien28-oic acid, stigmasterol, stigmasterol 3-O- $\beta$-Dglucopyranoside [3]. These compounds exhibited highly potent anti-yeast activity and active against enzymes of metabolic significance. Previous studies on the leave and stem-bark extracts reported pharmacological activities such as antibacterial and antifungal against a number of micro- organisms [6]-[10]. Chemical constituents of Terminalia mantaly has not been documented in the literature although its usage as an ornamental plant in Nigeria is known. It was therefore necessary to investigate the chemical composition of the essential oils of the plant so as to be able to suggest other areas of usage and applications.

\section{EXPERIMENTAL}

\section{A. Plant Materials}

Plants materials were collected from a mature tree growing in front of faculty of Science building University of Ibadan campus in February 2018. Authentication was conducted by Mr. P. Esimekhuai of Botany Department, University of Ibadan where herbarium specimen was filed with voucher number UIH-22719.

\section{B. Isolation of Essential Oil}

Plant materials were air dried and pulverized. The essential oils were isolated by hydro-distillation using all glass Clevenger-type apparatus for 4 hours according to the British Pharmacopoeia method. Pulverized leave (260 g), stembark $(423 \mathrm{~g})$ and twig (350 g) were immersed in water in a round bottom flask on a heating mantle. The extraction process was optimized with respect to time and temperature. The steam containing the essential oil was condensed and trapped using n-hexane in the Clevenger-type apparatus. The extracted essential oil was stored in a sealed - vial and refrigerated below $0{ }^{\circ} \mathrm{C}$ for further analysis. The yield of essential oils was calculated using the following expression. 


$$
Y=\frac{V \times 100}{W}
$$

where, $\mathrm{Y}$ is the yield of essential oil (\%); $\mathrm{V}$ is the volume of collected essential oil (ml) and $\mathrm{W}$ is the weight of the plant material used $(\mathrm{g})$.

\section{Gas Chromatography (GC)/Gas Chromatography -} Mass Spectrometric (GC-MS) Analyses

GC capillary column on which compounds were separated was Agilent hp-5, $30 \mathrm{~m}$ length, $0.25 \mu \mathrm{m}$ film thickness, $320 \mu \mathrm{m}$ ID. The Agilent 7890A GC ChemStation software was used to obtain the chromatogram.

GC-MS analyses were conducted on Agilent technology 7890A GC interfaced with a VL 70-250 cAnalytical double focusing MS 5975C. The operating parameter were: (a) GC:: fused silica column $(30 \mathrm{~m} \times 25 \mu \mathrm{m}$ i.d., $0.25 \mu \mathrm{m}$ phase thickness) coated with HP - 5MS (5\% Phenyl Methyl Silox); oven temperature programme $90{ }^{\circ} \mathrm{C}$ for $0 \mathrm{~min}$, then $3{ }^{\circ} \mathrm{C} / \mathrm{min}$ to $180{ }^{\circ} \mathrm{C}$; carrier gas, helium; flow rate $0.5 \mathrm{~mL} / \mathrm{min}$, average velocity $26.256 \mathrm{~cm} / \mathrm{sec}$ and a hold-up time of $1.9043 \mathrm{~min}$; (b) $\mathrm{MS}-\mathrm{EI}$ at $70 \mathrm{eV}$; ion source temperature $250{ }^{\circ} \mathrm{C}$.

\section{Identification of the Essential Oil Constituents}

Individual constituents were identified by matching their GC spectra with their mass spectral against those of authentic reference compounds as well as those published in the literature. National Institute of Standards and Technology (NIST) library database was used. In the actual sense, all of the chemical constituents listed in Table 1 were used for identification through co-injection and their retention rates were not obtained.

\section{RESUlts AND DisCUSSION}

The isolated essential oils from the leaf, stem-bark and twig by hydrodistillation afforded predominantly colourless volatile oils with various yields and characteristic odour. The leaf of T. mantaly has the highest yield quantity of $0.28 \%$, the stem-bark produced $0.13 \%$ while the twig has the lowest yield $0.11 \%$. The leaf essential oil exhibited a leafy odour, stem-bark produced woody smell and the twig produced an aromatic scent possibly as a result of the large presence of aromatic compounds in its oil.

Table 1 displays the chemical constituents identified by GC-MS of the volatile oil of the leaf, stem-bark and twig of Terminalia mantaly. A total of 44 compounds were identified with great variation in the composition of the three essential oils. Only two (Nonanal and aromadendrene) of the 44 compounds were common to all the three oils.

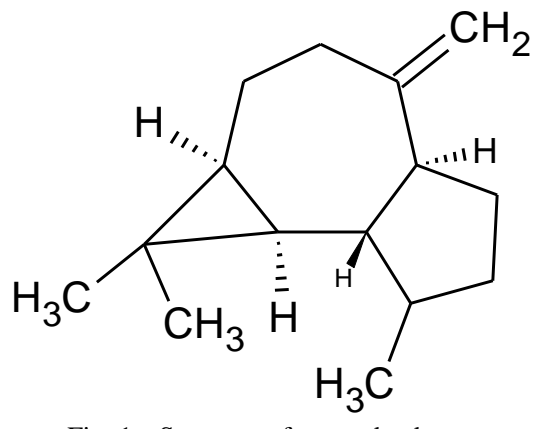

Fig. 1a. Structure of aromadendrene.<smiles>CCCCCCCCC=O</smiles>

Fig. 1b. Structure of nonanals.

TABLE I: VOLATILE OIL COMPOSITION OF VARIOUS PARTS OF TERMINALIA MANTALY

\begin{tabular}{|c|c|c|c|c|}
\hline \multirow{2}{*}{$\begin{array}{c}\begin{array}{c}\text { Retention } \\
\text { time }\end{array} \\
3.18\end{array}$} & \multirow{2}{*}{$\begin{array}{l}\text { Constituents } \\
\text { Ethylbenzene }\end{array}$} & \multicolumn{3}{|c|}{$\begin{array}{c}\% \text { Composition } \\
\text { Leaf Stem-bark Twig }\end{array}$} \\
\hline & & - & - & 2.95 \\
\hline 3.25 & $o$-Xylene & 6.02 & 4.54 & - \\
\hline 3.25 & $m$-Xylene & - & - & 21.98 \\
\hline 3.47 & Heptanal & - & 10.57 & - \\
\hline 3.49 & $p$-Xylene & - & - & 23.56 \\
\hline 4.678 & 2-Amylfuran & - & - & 2.69 \\
\hline 6.98 & Nonanal & 1.10 & 21.16 & 13.64 \\
\hline 8.53 & (E)-2-Nonenal & - & 1.41 & - \\
\hline 8.53 & 2-Butylacrolain & - & - & 1.89 \\
\hline 9.79 & Methyl Salicylate & 1.33 & - & - \\
\hline \multirow[t]{2}{*}{9.87} & Decanal & - & 4.61 & 4.08 \\
\hline & & - & - & 1.46 \\
\hline 13.81 & 2,4-Decadienal & - & 1.15 & - \\
\hline 14.57 & $\delta$-Elemene & - & 2.64 & - \\
\hline 16.63 & $\beta$-Elemene & 1.55 & - & - \\
\hline 17.71 & p-Methyl benzylol & - & 9.86 & - \\
\hline $\begin{array}{l}17.74 \\
17.98\end{array}$ & $\begin{array}{c}\text { Caryophyllene } \\
\alpha \text {-Ionone }\end{array}$ & 5.55 & - & - \\
\hline 18.16 & Dehydro- $\beta$-ionone & 3.42 & - & - \\
\hline 18.17 & $\gamma$-Elemene & - & 2.43 & - \\
\hline 18.80 & (E)-Geranylacetone & - & - & 1.56 \\
\hline 18.81 & Geranyl acetone & 9.06 & - & - \\
\hline 19.03 & Humulene & - & 3.45 & - \\
\hline 19.41 & Aromadendrene & 1.72 & 1.67 & 2.55 \\
\hline - & - & - & - & - \\
\hline 19.938 & $\alpha$-Amophene & - & 4.08 & - \\
\hline 20.18 & $\beta$-Ionone & 3.76 & - & - \\
\hline 20.19 & (E)- $\beta$-Ionone & - & - & 1.68 \\
\hline \multirow[t]{2}{*}{20.37} & $\beta$-Cadinene & - & 8.70 & - \\
\hline & & - & - & 1.38 \\
\hline 20.43 & 2-Tridecanone & - & 4.47 & - \\
\hline 20.97 & $\delta$-Cadinene & - & 0.87 & - \\
\hline 21.937 & $\gamma$-Cadiene & - & 1.83 & 2.68 \\
\hline 22.11 & $\alpha$-Gurjunene & - & 1.38 & - \\
\hline $\begin{array}{l}22.40 \\
22.68\end{array}$ & $\begin{array}{l}\alpha \text {-Calacorene } \\
\text { Elemol }\end{array}$ & - & 0.87 & - \\
\hline 23.07 & Nerolidol & - & - & 3.32 \\
\hline 23.10 & $\alpha$-Selinene & - & 1.20 & - \\
\hline 25.30 & Selina-6-en-4ol & - & 3.21 & - \\
\hline 25.53 & $\alpha$-Elemene & - & 1.63 & - \\
\hline 26.12 & $\tau$-Muurolol & - & 2.05 & - \\
\hline 26.60 & $\alpha$-Cadinol & - & 1.99 & - \\
\hline 27.09 & 8-heptadecene & - & - & 1.60 \\
\hline 33.09 & z-pinane & 16.71 & - & 3.69 \\
\hline 33.41 & $\begin{array}{l}\text { Perhydrofarnesyl } \\
\text { acetone }\end{array}$ & - & - & - \\
\hline 33.44 & $\begin{array}{l}\text { Hexahydrofarnesyl } \\
\text { acetone }\end{array}$ & 30.05 & - & - \\
\hline \multirow[t]{2}{*}{35.08} & 9-Octadecyne & 9.31 & - & - \\
\hline & & 89.51 & 95.77 & 95.92 \\
\hline
\end{tabular}

Serial number refers to order of elution from GC column.

Elution on a HP-5MS capillary column $(30 \mathrm{~m} \times 25 \mu \mathrm{m}$ i.d., $0.25 \mu \mathrm{m}$ phase thickness).

Twelve constituents, amounting to $89.51 \%$ were identified in the leaf essential oil of T. mantaly. Notable in the essential oil composition was the quantitative abundance of 
hexahydrofarnesylacetone (30.05\%) and Z-pinane (16.17\%). hexahydrofarnesylacetone being the only oxygenated sequiterpene derivative and Z-pinane as the only hydrocarbon monoterpene; making up to above half of the oil total composition. Substantial amount of 9-octadecyne (9.31\%), geranylacetone $(9.06 \%), o$-xylene $(6.02 \%)$ and $\alpha$-ionone $(5.55 \%)$ were recorded. Aromadendrene was the only sequiterpene identified in relatively low amount (1.72\%). In all, monoterpenoids accounted for $38.50 \%$, sesquiterpenoids $31.77 \%$, aliphatic hydrocarbons $10.32 \%$ and aromatic hydrocarbons $8.91 \%$. The intense odour of ionones isomers, ( $\alpha$ and $\beta$ ), identified in the volatile oil may possibly contribute substantially to the essential oil odour.

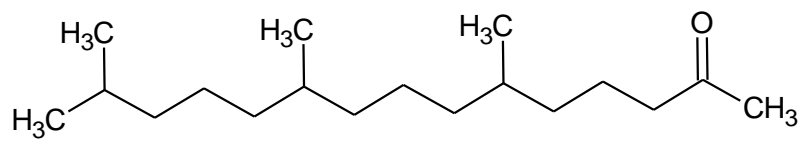

Fig. 2. Structure of hexahydrofarnesylacetone.

Significant qualitative and quantitative variations could be discerned on comparison of the compositional profile of the Nigerian T. mantaly leaf essential oils with previous published report for other Terminalia species. Terminalia catappa leaf essential oil was reported to have Z-phytol (41.2\%), palmitic acid (11.0\%) and E-nerolidol (4.7\%) as major components with alkane hydrocarbons accounting to $25.5 \%$ [11]. Noteworthy is the absence of these main constituents in T. mantaly leaf volatile oil; two constituents, methyl salicylate and geranyl acetone, out of the sixty-six compounds identified in $T$. catappa was detected in $T$. mantaly leaf essential oil with quantitative different. The volatile leaf oil of Terminalia bentzoe [12] was characterized mainly with citronellyl acetate $(64.87 \%)$ and neral $(23.24 \%)$. These monoterpenoids were not found in T.mantaly leaf essential oil. The composite of T. bentzoe chemical profile is not in any way similar to those of the $T$. mantaly. These qualitative and quantitative variations in the chemical profile of the essential oils of Terminalia species with other results from the same plant across the country and the world may be suggested for the chemotypic form of the plant.

A total of twenty-three constituents were identified in the stem-bark volatile oil. The identified compounds made up $95.77 \%$ of the oil. Notable in the essential oil composition was the quantitative abundance of aliphatic aldehydes namely nonanal $(21.16 \%)$ and heptanal $(10.57 \%)$ with significant proportion of caryophyllene $(9.86 \%)$ and $\beta$-cadinene $(8.70 \%)$. The essential oil of the stem-bark was characterized by high amount of sesquiterpenoids (53.48\%) although aliphatic aldehydes were the chief constituents. Worth mentioning was the absence of monoterpenoid terpenes and the detection of $o$-xylene $(4.54 \%)$ as the only aromatic hydrocarbon. The diffusive pungent harsh odour of nonanal, one of the principal constituents of the volatile oil, may be responsible for the pungency in the oil scent. The four isomers $(\alpha, \beta, \gamma, \delta)$ of elemene may also contribute to the volatile oil aroma.

Four sequiterpene alcohols - elemol, selina-6-en-4ol, $\tau$ muurolol, $\alpha$-cadinol were detected in the stem-bark essential oil with percentage composition of $0.87 \%, 3.21 \%, 2.05 \%$, $1.99 \%$ respectively. These compounds may contribute to the volatile oil biological activities such as, antioxidant and antimicrobial [13], as a result of their lipophillic and hydrophilic character they possess.

The 17 compounds out of 22 compounds found in the twig essential oil made up $95.92 \%$, with $m$-xylene $(21.98 \%)$ and $p$-xylene $(23.56 \%)$ as the major component. Sizable amount of perhydrofarnesyl acetone (5.21\%), Z-pinane (3.69\%) and nerolidol $(3.32 \%)$ were terpenoids which occur in sizable amount while others are between $1.38 \%-2.68 \%$. Aromatic and aliphatic hydrocarbons constituted a predominant portion of the oil, $51.18 \%$ and $24.05 \%$ correspondingly. Three unidentified aliphatic amines were identified in trace amount $(0.79-0.85 \%)$. The aromatic aroma of the twig essential oil may perhaps be a result of the identified benzene derivatives in the oil.

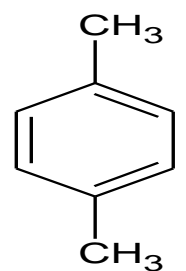

Fig. 3. p-xylene

\section{CONCLUSION}

The essential oils of $T$. mantaly have been investigated before now. Consequently, these finding are being recorded for the first time. The chemical composition of the Terminalia mantaly leaf, stem-bark and twig essential oils varied greatly quantitatively and qualitatively, this variation could be owned to the existence of diverse secretory structures that are heterogeneously distributed over the plant body [(14)]. With these data, other therapeutic application of these plants could be considered.

\section{APPENDIX}

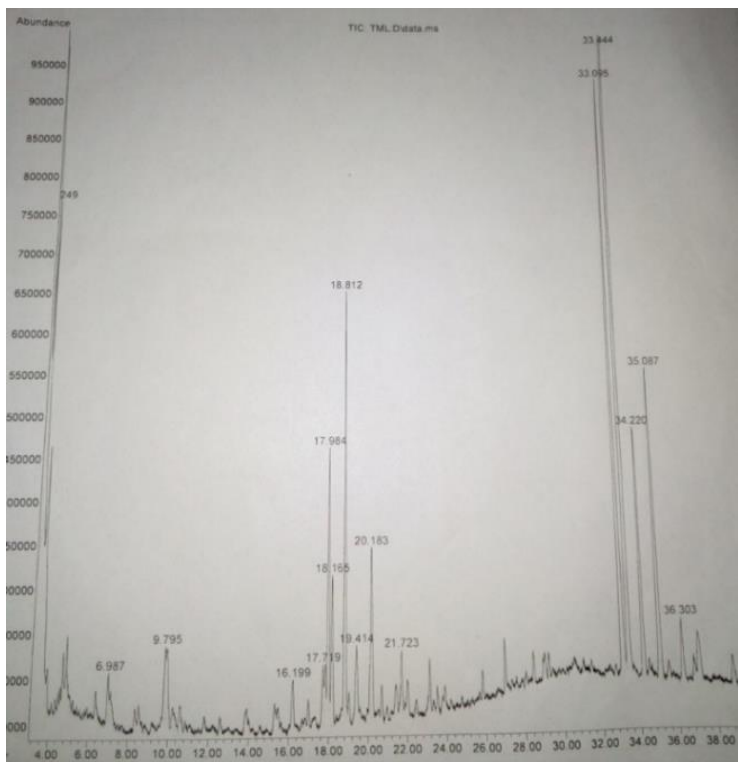

Fig. 4. GC chromatogram of the leave of Terminalia mantaly H. Perrier. 


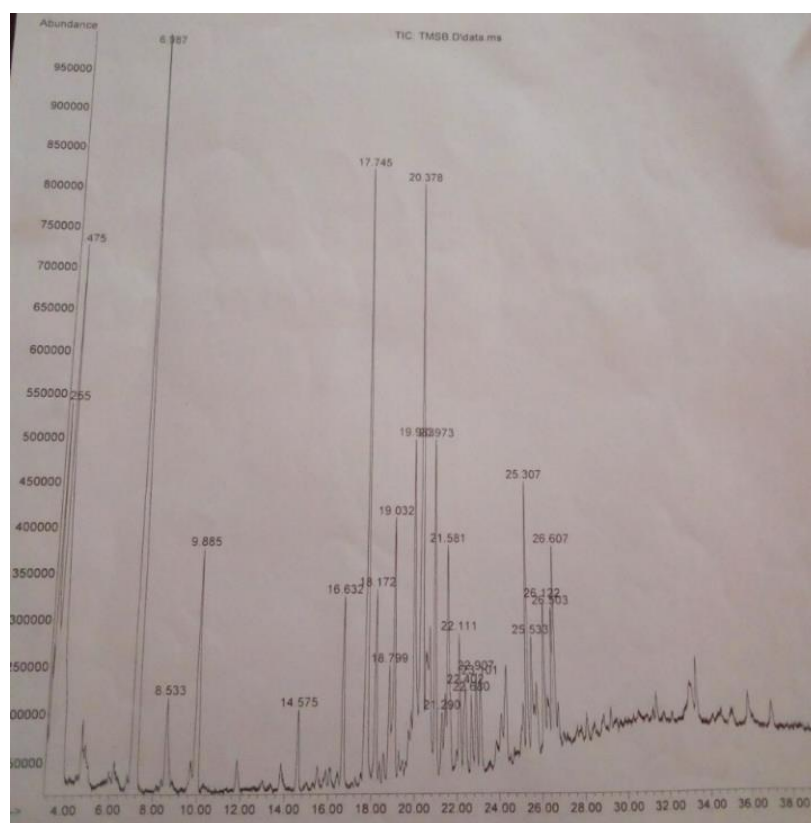

Fig. 5. GC chromatogram of the stembark of Terminalia mantaly H. Perrier.

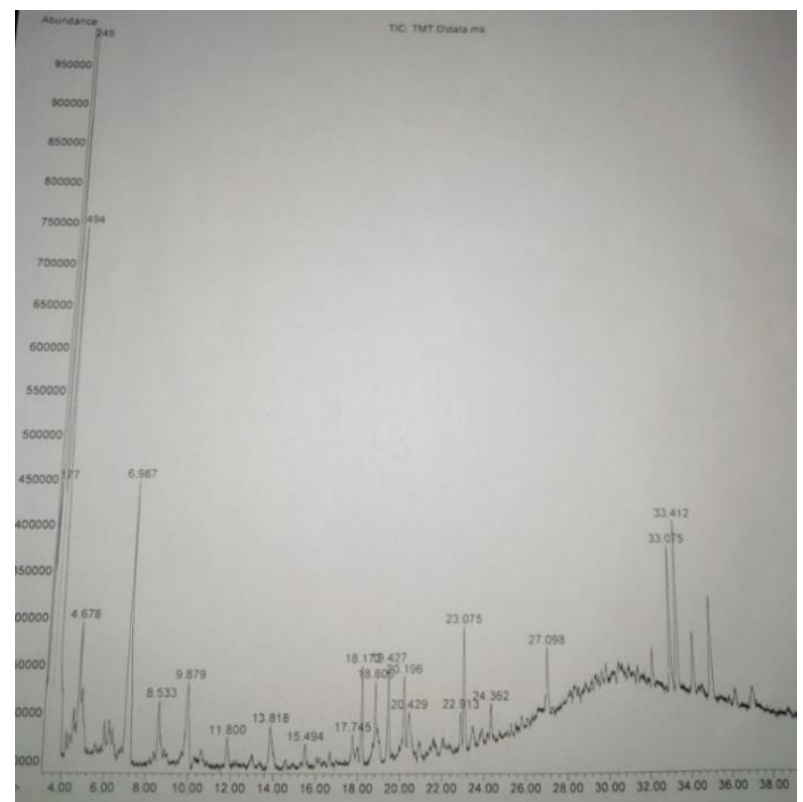

Fig. 6. GC chromatogram of the twig of Terminalia mantaly H. Perrier.

\section{ACKNOWLEDGMENT}

To Professor O. Ekundayo who supervised this work and enlightened in the area of research (but decided not to be part of the authors). The technical assistance of Mr. Femi in the analyses of the essential oils and collection of plant material by $\mathrm{Mr}$ I. Okunlola is gratefully acknowledged. Dr. S.A Aboaba and Miss U. M Oghenejoboh are appreciated for their assistance with the requisite apparatus used.

\section{REFERENCES}

[1] N. L. Edwin-Wosu and T. Omara-Achong, "Ecogeographical Amplitude," J. Appl. Sci. Environ. Manag. 17, 75-80, 2013.

[2] C. Orwa, A. Mutua, R. Kindt, R. Jamndass, and A. Simon, "Database: A tree reference and selection guide version" (http//www.worlagroforest 1-5) 2009

[3] T. M. Tohuente Tchuenmogne, T. N. Kammalac, S. Gohlke, et. al. "Compounds from Terminalia mantaly L. (Combretaceae) Stem Bark
Exhibit Potent Inhibition against Some Pathogenic Yeasts and Enzymes of Metabolic Significance" Medicines 4, 6. 2017.

[4] K. Coulibaly, "Evaluation of the Antifungal Activity of Extracts of Bark of Commercial Species" Category P1 the Forest of Mopri, Tiassale (Southern Ivory Coast). Memory Master In Tropical Ecology, Plant option, University of Cocody-Abidjan, Department of Bioscience. 23-25, 2006.

[5] B. E. Kamo IL, et. al. "Assessment of toxic effects of hydro-alcoholic extract of Terminalia mantaly $\mathrm{h}$. Perrier (Combretaceae) via hematological evaluation in rats" Pharma Innov. J. 3, 34-40, 2015.

[6] P. Kokora, et. al. "Antibacterial Activity of Ethanolic and Aqueous Extracts of Four Medicinal Plants on the in vitro Growth of Escherichia coli and Staphylococcus aureus"J. Drug Deliv. Ther. 3, 113-116, 2013

[7] J. Ackah, et. al. "Action Spectrum of Terminalia Mantaly on the In Vitro Growth of Pseudomonas" Int. J. Pharm. Res. Sch. (IJPRS) 3, 795-800, 2014.

[8] T. Ngouana, et. al. "Potent and Synergistic Extract Combinations from Terminalia Catappa, Terminalia Mantaly and Monodora tenuifolia Against Pathogenic Yeasts" Medicines 2, 220-235, 2015.

[9] A. A. B. A. Jacques, Y. Y. Guillaume, Y. H. Felix, K. M. K. Adou, and D. A. Joseph, "Antifungal Activity of Terminalia mantaly on the in vitro Growth of Cryptococcus neoformans" Int. J. Biochem. Res. Rev. 3, 63-73, 2013.

[10] O. Abou, K. K. Elisée, M. S. Vénérer, and K. Ibrahim, "Study of the antibacterial activity of bark extracts from Terminalia mantaly (Combretaceae) on the in vitro growth of eight (8) clinical enterobacteria strains" J. Medicianal Plants Stud. 6, 101-105, 2018.

[11] M. S. Owolabi, O. A. Lawal, I. A. Ogunwande, R. M. Hauser, and W. N. Setzer, "Chemical composition of the leaf essential oil of Terminalia catappa L. growing in southwestern Nigeria" Am. Journal Essent. Oils Nat. Prod. 1, 51-54, 2013.

[12] A. Gurib-fakim and D. Frédérick, "Essential Oil of Terminalia bentzoë (L.) L . f . subsp . rodriguesensis Wickens. J. Essent” Oil Res. 6, 533534, 2015.

[13] A. R. Koroch, H. R. Juliani, and J.A. Zygadlo, "Bioactivity of Essential Oils and Their Components in Flavours and Fragrances: Chemistry, Bioprocessing and Sustainability" Springer (ed. Berger, R.) 87-115, 2007.

[14] C. Figueiredo, J. Barroso, L. Pedro and J. Scheefeer, "Factors affecting secondary metabolite production in plants: Volatile components and essential oils. Flavour Fragr. J. 22, 206-213, 2007.

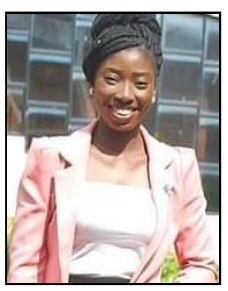

Owoade, O. M. was born in Oyo State, Nigeria in 1993 and bagged her first degree (B.sc honours) in Industrial Chemistry from Bowen University (2015) and her Masters' degree (M.sc) In Organic Chemistry from the University of Ibadan (2018).

She has worked as laboratory assistance at DOP's soap company in Lagos State and as a Practical Demonstrator at University of Ibadan, Ibadan respectively in Nigeria.

She currently works as a subject teacher (Chemistry) at Aipate Baptist Church Grammar School, Iwo, Nigeria.

Miss Owoade is a member of the Student Chemical Society of Nigeria (SCSN). She was awarded the Dean's honour roll award, Bowen University, Iwo, Nigeria (2013).

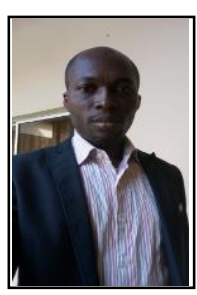

Oke D.G was born in Bauchi, State, Nigeria in 1977 and was educated at Abubakar Tafawa Balewa University, Bauchi for his first degree in Industrial Chemistry (2003) and at University of Lagos, Nigeria for his second degree in Organic Chemistry (2012) and another Master's degree in Organic Chemistry at Bowen University, Iwo, Nigeria in Organic Chemistry (2016).

He has worked as a manager at a construction company and as a trainer in an electronic board deployment company in Bauchi and Lagos states respectively in Nigeria. He presently works as a lecturer at Bowen University, Iwo, Nigeria. Mr. Oke is a member of Chemical Society of Nigeria and an Associate member of Royal Society of Chemistry. 